\title{
COLLISION OF FOUR BALLS ALIGNED
}

\author{
Othman Ben Mekki ${ }^{1}$ and Michel Frémond ${ }^{2}$ \\ ${ }^{1}$ Università di Roma "Tor Vergata", Italy \\ ${ }^{2}$ Laboratoire Central des Ponts et Chausses, France
}

\begin{abstract}
The collision of four balls aligned is analyzed in this paper. This study is based on the fundamental idea that a system formed by rigid bodies is deformable, since its shape changes because the relative distances of the different bodies change. A simple linear constitutive law, described by a pseudo-potential of dissipation completed by the condition of the impenetrability between the balls, is used. we consider the case where three balls falls on a very massive obstacle. The first ball, considered of very light mass, bounces with a velocity extensively superior to its fall velocity. This is sometimes called the superball phenomenon.

This phenomenon is produced according to different cases such as the interaction between the first ball and the massive obstacle must be presented. Introducing an interaction between the first ball and the massive obstacle through the second or the third ball, the superball phenomenon is produced for all cases of evolutions after the collision. For every cases of evolutions of the balls after the collision, has been investigated the relations on the physical parameters which insure the superball phenomenon. These relations are obtained on the basis of the fundamental hypothesis: the mass of the first ball is very small whereas the mass of the massive obstacle is very large.
\end{abstract}

\section{INTRODUCTION}

Let us consider a heavy ball with mass $m_{3}$ on which rest two other balls with masses $m_{2}$ and $m_{1}$. These balls fall on a very massive obstacle with mass $m_{4}$, Fig. 1 . Mass $m_{1}$ is assumed to be very small. Experiments show that when the three balls collide the very massive obstacle, ball 1 rebounds with a very large upward velocity. We intend to give a predictive theory accounting for this spectacular phenomenon, which is sometimes called the superball phenomenon $[1,2]$. Experiments are more easy to perform with three balls: ball 1 is a tennis table ball, ball 2 is a soccer ball, ball 3 and 4 are the massive obstacle.

We assume the ball masses are concentrated at their mass center. Thus they are treated as points (this is equivalent to assume that their mass moment of inertia is equal to zero). The considered system is made of four points: the three balls and the very massive obstacle moving along a vertical axis directed upward. This system is deformable because the relative position of its four elements changes. To describe the velocity of deformation 


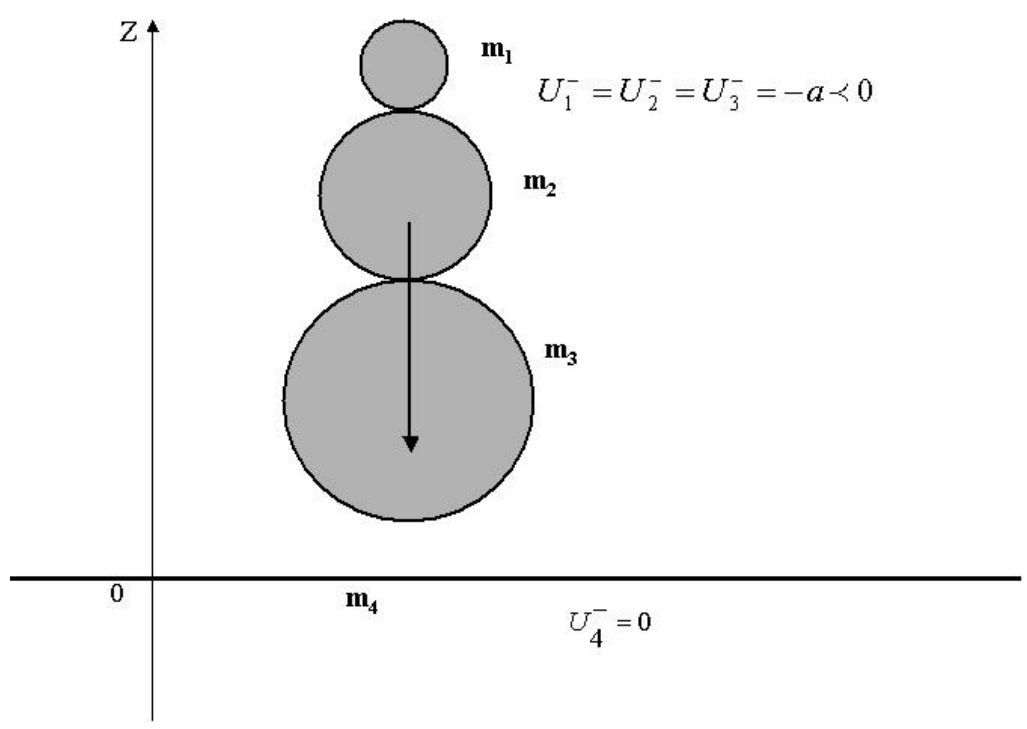

Fig. 1. Collision of four balls moving along a vertical axis

of the system, we choose the relative velocities

$$
D_{i j}(U)=U_{i}-U_{j}, \quad i=1 . .3, \quad j=2 . .4 \quad \text { and } \quad i<j,
$$

with $U=\left(U_{1}, U_{2}, U_{3}, U_{4}\right)$ and $U_{i}$ are the actual velocities of the ball $i$. In the sequel we focus only on collisions, which are assumed instantaneous [3-5]: it is denoted $A^{+}$and $A^{-}$the value of a quantity $\mathrm{A}$ after and before the collision and $[A]=A^{+}-A^{-}$is the discontinuity of the quantity $\mathrm{A}$ in the collision.

\section{THE EQUATIONS OF MOTION}

The equations of motion of the balls result from the principle of the virtual work $[4,5]$. The virtual velocities of the system in a collision are $V=\left(V^{+}, V^{-}\right)$

$$
\left\{\begin{array}{l}
V^{+}=\left(V_{1}^{+}, V_{2}^{+}, V_{3}^{+}, V_{4}^{+}\right) \\
V^{-}=\left(V_{1}^{-}, V_{2}^{-}, V_{3}^{-}, V_{4}^{-}\right)
\end{array}\right.
$$

where $V^{+}$and $V^{-}$are the velocities after and before the collision of the four balls.

The virtual work of the acceleration forces in a collision is

$$
\Gamma_{a c c}(V)=m_{1}\left[U_{1}\right] \frac{V_{1}^{+}+V_{1}^{-}}{2}+m_{2}\left[U_{2}\right] \frac{V_{2}^{+}+V_{2}^{-}}{2}+m_{3}\left[U_{3}\right] \frac{V_{3}^{+}+V_{3}^{-}}{2}+m_{4}\left[U_{4}\right] \frac{V_{4}^{+}+V_{4}^{-}}{2} .
$$

Because the system is deformable, with deformation velocities $D_{i j}(U)$, there are internal forces which are percussions. Their virtual work in a collision is [3]

$$
\begin{aligned}
& \Gamma_{i n t}(V)=-P_{12} D_{12}\left(\frac{V^{+}+V^{-}}{2}\right)-P_{13} D_{13}\left(\frac{V^{+}+V^{-}}{2}\right)-P_{14} D_{14}\left(\frac{V^{+}+V^{-}}{2}\right) \\
& -P_{23} D_{23}\left(\frac{V^{+}+V^{-}}{2}\right)-P_{24} D_{24}\left(\frac{V^{+}+V^{-}}{2}\right)-P_{34} D_{34}\left(\frac{V^{+}+V^{-}}{2}\right)
\end{aligned}
$$


where $P_{i j}$ are the interior percussions which describe the interactions between the different balls of the system. It is to be remarked that in this general setting at a distance actions occur between the different balls. The principle of virtual work assuming there are no external percussion

$$
\forall V \quad \Gamma_{\text {int }}(V)=\Gamma_{a c c}(V),
$$

gives the equations of motion:

$$
\left\{\begin{array}{l}
m_{1}\left[U_{1}\right]=-P_{12}-P_{13}-P_{14} \\
m_{2}\left[U_{2}\right]=P_{12}-P_{23}-P_{24} \\
m_{3}\left[U_{3}\right]=P_{13}+P_{23}-P_{34}, \\
m_{4}\left[U_{4}\right]=P_{14}+P_{24}+P_{34} .
\end{array}\right.
$$

\section{THE CONSTITUTIVE LAWS}

Constitutive laws needed for the interior forces, have to satisfy the second law of thermodynamics $[2,5]$. We know it is satisfied by constitutive laws defined with a pseudopotential of dissipation $\phi\left(D_{i j}\right)$ (a pseudo-potential of dissipation as defined by [6] is a convex, positive function with value zero at the origin). For the sake of simplicity we choose a quadratic pseudo-potential function with indicator functions taking into account the impenetrability of the different balls $\left(U_{1}^{+}>U_{2}^{+}, U_{2}^{+}>U_{3}^{+}\right.$and $\left.U_{3}^{+}>U_{4}^{+}\right)$.

$$
\phi(X)=X^{T} M X+I_{+}\left(U_{1}^{+}-U_{2}^{+}\right)+I_{+}\left(U_{2}^{+}-U_{3}^{+}\right)+I_{+}\left(U_{3}^{+}-U_{4}^{+}\right)
$$

with $X^{T}=\left(X_{12}, X_{13}, X_{14}, X_{23}, X_{24}, X_{34}\right), X_{i j}=D_{i j}\left(\frac{U^{+}+U^{-}}{2}\right)$ and dissipative matrix $M$ is

$$
M=\left(\begin{array}{cccccc}
K_{12} & \alpha_{1} & \alpha_{2} & 0 & 0 & 0 \\
\alpha_{1} & K_{13} & \alpha_{3} & 0 & 0 & 0 \\
\alpha_{2} & \alpha_{3} & K_{14} & \alpha_{4} & \alpha_{5} & \alpha_{7} \\
0 & 0 & \alpha_{4} & K_{23} & \alpha_{6} & 0 \\
0 & 0 & \alpha_{5} & \alpha_{6} & K_{24} & 0 \\
0 & 0 & \alpha_{7} & 0 & 0 & K_{34}
\end{array}\right)
$$

For the sake of simplicity, we introduced in matrix $M$, where the coefficients $\alpha_{i}$ that relate the first ball with the fourth. The six $K_{i j}$ and the seven $\alpha_{i}$ parameters satisfy relations which insure that matrix $M$ of the quadratic function is positive semi-definite, in order that $\phi$ is a pseudo-potential:

$$
\begin{aligned}
& K_{i j}>0, \alpha_{1}^{2} \leq K_{12} K_{13}, \alpha_{2}^{2} \leq K_{12} K_{14}, \alpha_{3}^{2} \leq K_{13} K_{14}, \alpha_{4}^{2} \leq K_{14} K_{23}, \alpha_{5}^{2} \leq K_{14} K_{24}, \\
& \alpha_{6}^{2} \leq K_{23} K_{24}, \alpha_{7}^{2} \leq K_{14} K_{34}, K_{12} K_{13} K_{14}+2 \alpha_{1} \alpha_{2} \alpha_{3} \geq K_{12} \alpha_{3}^{2}+K_{13} \alpha_{2}^{2}+K_{14} \alpha_{1}^{2} \\
& K_{14} K_{23} K_{24}+2 \alpha_{4} \alpha_{5} \alpha_{6} \geq K_{14} \alpha_{6}^{2}+K_{23} \alpha_{5}^{2}+K_{24} \alpha_{4}^{2} .
\end{aligned}
$$

The constitutive laws are:

$$
P_{i j}=\frac{\partial \phi}{\partial X_{i j}}\left(D\left(\frac{U^{+}+U^{-}}{2}\right)\right)
$$

or

$$
P_{12}=2 K_{12} X_{12}+2 \alpha_{1} X_{13}+2 \alpha_{2} X_{14}+P_{12}^{\text {reac }},
$$

with $P_{12}^{r e a c} \in \partial I_{+}\left(D_{12}\left(U^{+}\right)\right)$. 
Function $I_{+}$is the indicator function of the set of the positive numbers $\mathbf{l R}^{+}, \partial I_{+}$is its subdifferentiel set [7]. The last relation insures impenetrability of balls 1 and 2, reaction $P_{12}^{r e a c}$ is only activated if there is a risk of interpenetration, i.e. if contact is maintained after the collision; $D_{12}\left(U^{+}\right) \leq 0$.

$$
\begin{gathered}
P_{13}=2 K_{13} X_{13}+2 \alpha_{1} X_{12}+2 \alpha_{3} X_{14} \\
P_{14}=2 K_{14} X_{14}+2 \alpha_{2} X_{12}+2 \alpha_{3} X_{13}+2 \alpha_{4} X_{23}+2 \alpha_{5} X_{24}+2 \alpha_{7} X_{34}, \\
P_{23}=2 K_{23} X_{23}+2 \alpha_{4} X_{14}+2 \alpha_{6} X_{24}+P_{23}^{\text {reac }},
\end{gathered}
$$

with $P_{23}^{r e a c} \in \partial I_{+}\left(D_{23}\left(U^{+}\right)\right)$,

$$
\begin{gathered}
P_{24}=2 K_{24} X_{24}+2 \alpha_{5} X_{14}+2 \alpha_{6} X_{23}, \\
P_{34}=2 K_{34} X_{34}+2 \alpha_{7} X_{14}+P_{34}^{\text {reac }},
\end{gathered}
$$

with $P_{34}^{\text {reac }} \in \partial I_{+}\left(D_{34}\left(U^{+}\right)\right)$.

Assuming the velocities before the collision $U^{-}$are known, it is proved that the system formed by constitutive laws (7-12) and equation of motion (5) have an unique solution to velocities after collision.

\section{EXAMPLES}

Depending on seventeen physical parameters $m_{i}, K_{i j}$ and $\alpha_{i}$, there are six possible evolution of the four balls after collision:

- Case 1: the very light ball bounces and the two heavy solids remain in contact with the massive obstacle.

- Case 2: the two light balls bounce and the heavy solid remains in contact with the massive obstacle. Depending for its mass, the second ball may or may not remain in contact with the first ball after the collision; one can have two possible subcases:

- Case 2.1: the two balls that bounce remain in contact after collision.

- Case 2.2: the two balls that bounce don't remain in contact after collision.

- Case 3: the three balls bounce. Depending on the masses of the two intermediate balls, there are three possible subcases:

- Case 3.1: the balls number 1 and 2 remain in contact after collision.

- Case 3.2: the balls number 2 and 3 remain in contact after collision.

- Case 3.3: the three balls don't remain in contact after collision.

For every case we look for conditions on parameters which insure the superball phenomenon: the small ball bounces with a velocity larger than its incoming velocity. We think that the superball phenomenon occurs only if there is an interaction between the very light ball number 1 and ball number $4\left(K_{14}>0\right.$ is very large). In this situation the interaction between the balls 1 and 4 is produced:

- by an interaction through ball 2 ,

- by an interaction through ball 3,

- by an interaction through ball 2 and 3 together,

- by a direct interaction. 
We choose to investigate in the sequel

- Case 1, depending on $\alpha_{2}$,

- Case 2.1, depending on $\alpha_{1}$ and $\alpha_{6}$,

- Case 3.2, depending on $\alpha_{5}$,

- Case 3.3, depending on $\alpha_{4}$.

The last case is analyzed numerically because the formal calculation is too heavy. For four cases investigated in the next paragraphs, the velocities before the collision of the first three balls are equal; $U_{1}^{-}=U_{2}^{-}=U_{3}^{-}=-a$, and the velocity of the very massive obstacle is zero. Where $-a$ is the falling velocity with $a=\sqrt{2 g h}$ where $h$ is the height of fall.

\subsection{Case 1: The very light ball bounces and the two heavy solids remain in contact with the massive obstacle}

As already said; we looked for conditions in order have the superball phenomenon. We assume $\alpha_{2} \neq 0$ and the others $\alpha_{i}=0$.

It is looked for conditions on the physical parameters such that

$$
U_{1}^{+}>a, \quad U_{2}^{+}=U_{3}^{+}=U_{4}^{+}=U^{+} \leq 0 \quad \text { and } \quad P_{23}^{r e a c}<0, \quad P_{34}^{\text {reac }}<0
$$

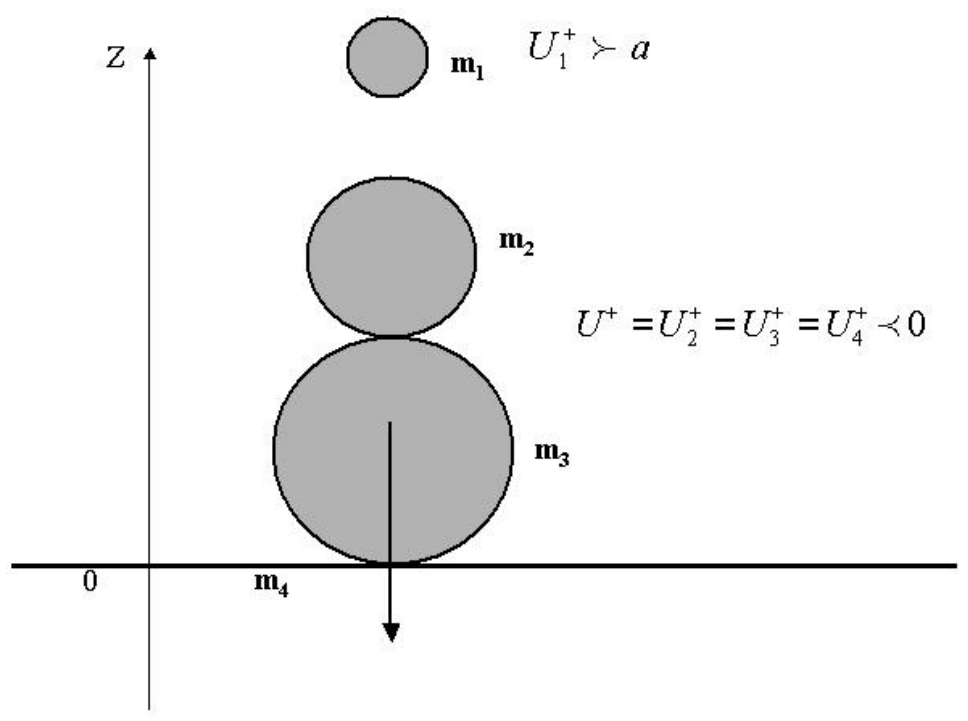

Fig. 2. The very light ball bounces and the two heavy solids remain in contact with the massive obstacle

The very light ball bounces with a velocity larger than its falling velocity and the two heavy solids remain in contact with the massive obstacle, Fig. 2. To obtain those 
conditions, the system formed by the equations of constitutive laws and the equations of motion is solved assuming the three first relations of (13) are satisfied. Then checking that the resulting velocities $U_{i}^{+}$and the reactions $P_{23}^{r e a c}$ and $P_{34}^{r e a c}$, unknown of the problem, depending on the physical parameters have the convenient properties, it results the conditions on parameters. Because it is known the solution to be unique, the conditions insure that the actual evolution is the one characterised by inequalities (13). Assuming that $m_{4}$ and $K_{14}$ are very large compared to the others quantities, the conditions are:

$$
-\alpha_{2}>2 m_{1}+K_{12}+K_{13},
$$

to have the superball phenomenon $\left(U_{1}^{+}>a\right)$;

$$
m_{1}<K_{14}+\alpha_{2},
$$

to describe the actual evolution $\left(U_{1}^{+}>U^{+}\right)$;

$$
\alpha_{2}\left(\alpha_{2}+2 m_{2}\right) \geq K_{14}\left(K_{12}+K_{24}+2 \alpha_{2}-m_{2}\right),
$$

to insure non interpenetration between balls 2 and $3\left(P_{23}^{\text {reac }} \leq 0\right)$;

$$
m_{2}+m_{3} \geq K_{12}+K_{13}+K_{24}+K_{34},
$$

to insure non interpenetration between balls 3 and $4\left(P_{34}^{\text {reac }} \leq 0\right)$.

Those conditions are similar to the case of collision of three balls valued by [2] when the very light ball bounces and the heavy solid remains in contact with the massive obstacle.

The velocity of small ball is

$$
U_{1}^{+}=a \frac{K_{14}+\alpha_{2}-m_{1}}{m_{1}+K_{12}+K_{13}+K_{14}+2 \alpha_{2}}
$$

If we choose $K_{12}=-\alpha_{2}\left(1-\varepsilon+\varepsilon^{2}\right), K_{13}=-\alpha_{2} \varepsilon^{2}, K_{14}=-\alpha_{2}(1+\varepsilon)$ and $m_{1}=-\alpha_{2} \varepsilon^{3}$ satisfy the last relations, the velocity of ball 1 after the collision is very large and its value is

$$
U_{1}^{+}=a \frac{1}{2 \varepsilon}
$$

Remark: If we replace $\alpha_{2}$ by $\alpha_{3} ; \alpha_{3}$ is different from zero and all others $\alpha_{i}$ are zero, we will also have the superball phenomenon. On the other hand, if we assume $\alpha_{1}$ and $\alpha_{6}$ to be different from zero an all the other $\alpha_{i}$ are zero, it is not possible to have the superball phenomenon.

\subsection{Case 2.1: The two light balls bounce and remain in contact and the heavy solid remains in contact with the very massive obstacle after the collision}

We analyze this case where the two light balls that bounce remain in contact and the heavy solid remains in contact with the very massive obstacle after the collision, Fig. 3 , we assume $\alpha_{1}$ and $\alpha_{6}$ are different from zero and all others $\alpha_{i}$ are zero. The unknowns of the problem are: the velocity of the first and second ball that remain in contact $U_{12}^{+}$, the reaction between them $P_{12}^{r e a c}$, the velocity of the third ball and the very massive obstacle that remain in contact $U_{34}^{+}$and the reaction between them $P_{34}^{r e a c}$. It is looked for conditions on parameters $m_{i}, K_{i j}, \alpha_{1}$ and $\alpha_{6}$ such that

$$
U_{12}^{+}>a, \quad U_{34}^{+} \leq 0, \quad P_{12}^{r e a c} \leq 0 \quad \text { and } \quad P_{34}^{r e a c} \leq 0 .
$$


Assuming that $m_{4}$ and $K_{14}$ are very large compared to the others quantities, the conditions are:

$$
-\alpha_{6}>2\left(m_{1}+m_{2}\right)+\left(K_{13}+K_{23}\right),
$$

to have the superball phenomenon $\left(U_{12}^{+}>a\right)$;

$$
\alpha_{1}>\alpha_{6}-m_{3}-2\left(m_{1}+m_{2}\right)
$$

to describe the actual evolution $\left(U_{34}^{+} \leq 0\right)$;

$$
\alpha_{1} \geq 2 m_{2}+\alpha_{6}+K_{23}-K_{24},
$$

of non interpenetration between the balls 1 and $2\left(P_{12}^{\text {reac }} \leq 0\right)$;

$$
\alpha_{1} \geq-m_{3}+\alpha_{6}+K_{13}+K_{23}+K_{34},
$$

of non interpenetration between the balls 1 and $2\left(P_{34}^{\text {reac }} \leq 0\right)$.

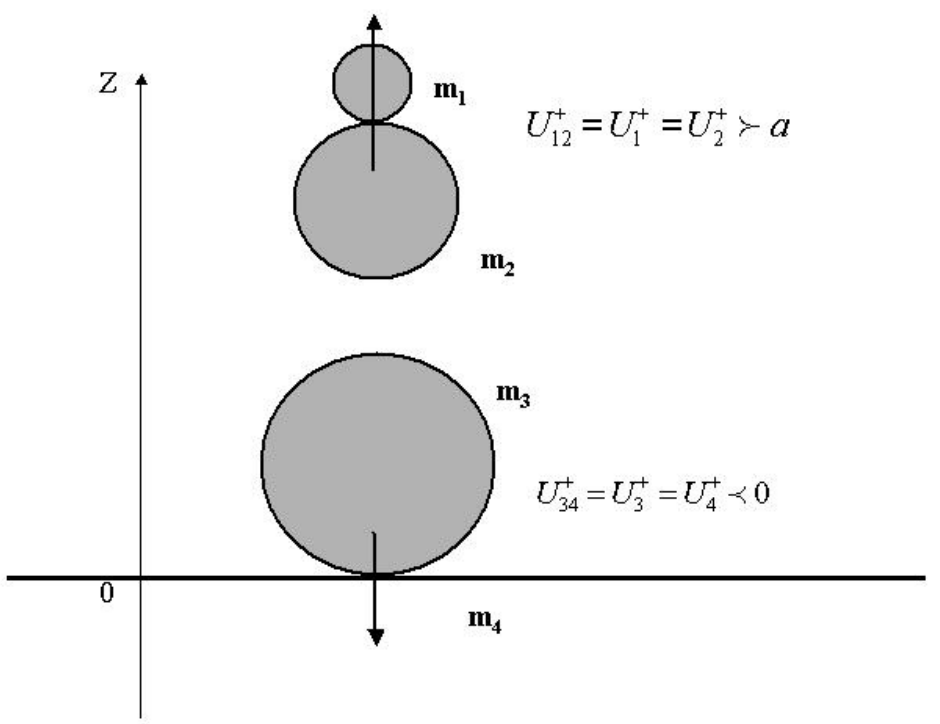

Fig. 3. The two light balls bounce and remain in contact and the heavy solid remains in contact with the very massive obstacle after the collision

By having the coefficients $\alpha_{1}$ and $\alpha_{6}$ different from zero, that we call by weak interaction, we have the superball phenomenon. The found conditions are similar to those found in the case of collision of three balls, where the small ball bounces and the massif solid remains in contact with the very massive obstacle [2]. 


\subsection{Case 3.2: The three balls bounce with 2 and 3 remain in contact after the collision}

This case is investigated analytically assuming $\alpha_{5} \neq 0$ and all others $\alpha_{i}=0$. The unknowns of the problem are: the velocity of the first ball, velocity of the second and third ball that remain in contact, the reaction between them and velocity of the obstacle massif (Fig. 4). It is looked for conditions on parameters $m_{i}, K_{i j}$, and $\alpha_{5}$ such that

$$
U_{1}^{+}>a, \quad U^{+}<U_{1}^{+}, \quad U_{4}^{+}<U^{+} \text {and } P_{23}^{\text {reac }}<0
$$

with $U^{+}=U_{2}^{+}=U_{3}^{+}$. To obtain those conditions, the system formed by the equations of constitutive laws and the equations of motion is solved assuming the three first relations of (15) are satisfied. Then checking that the resulting velocities $U_{i}^{+}$and the reactions $P_{23}^{r e a c}$, unknown of the problem, depending on the physical parameters have the convenient properties, it results the conditions on parameters, such as the $m_{4}$ and $K_{14}$ are large enough compared to the others quantities.

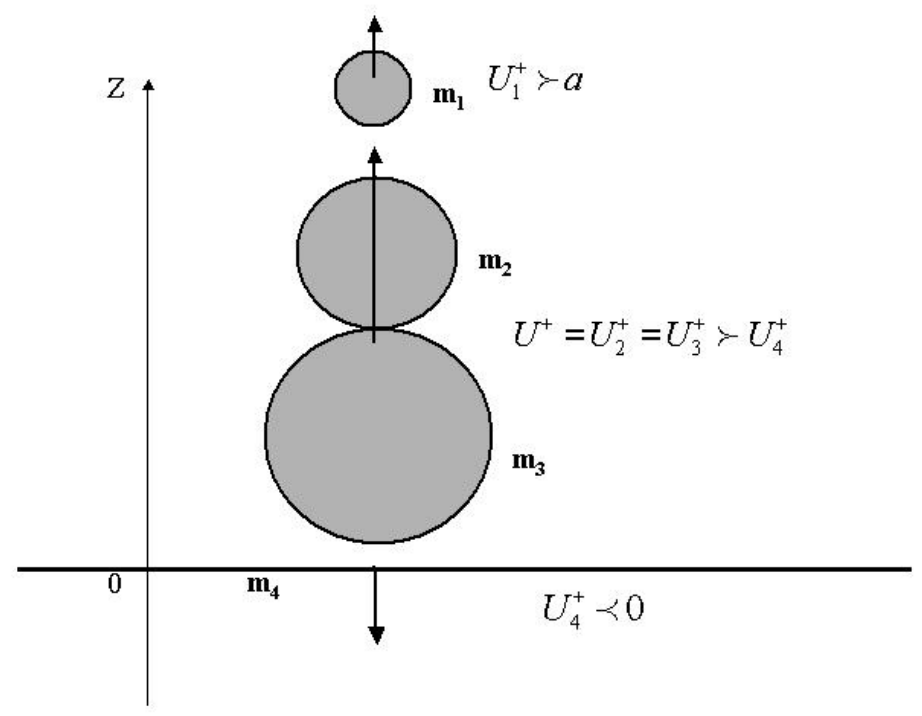

Fig. 4. The three balls bounce with 2 and 3 remain in contact after the collision

The conditions are:

$$
2 m_{1}+K_{12}+K_{13}-2 \alpha_{5}>0,
$$

to have the superball phenomenon $\left(U_{1}^{+}>a\right)$;

$$
\left(m_{2}+m_{3}\right)\left(K_{14}+\alpha_{5}\right)<m_{1}\left(K_{24}+K_{34}+\alpha_{5}\right)
$$

to describe the actual evolution $\left(U_{1}^{+}>U^{+}\right)$;

$$
\alpha_{5}^{2} \leq K_{24} K_{14}, \quad m_{2}+m_{3}<K_{24}+K_{34},
$$


to obtain the actual evolution $\left(U^{+}>U_{4}^{+}\right)$;

$$
m_{2}\left(K_{13}+K_{34}\right)<m_{3}\left(K_{12}+K_{24}\right),
$$

of non interpenetration between the balls 2 and $3\left(P_{23}^{\text {reac }} \leq 0\right)$.

Remark If we replace $\alpha_{5}$ by $\alpha_{7} ; \alpha_{7} \neq 0$ and all others $\alpha_{i}$ are zero, we will also have the superball phenomenon.

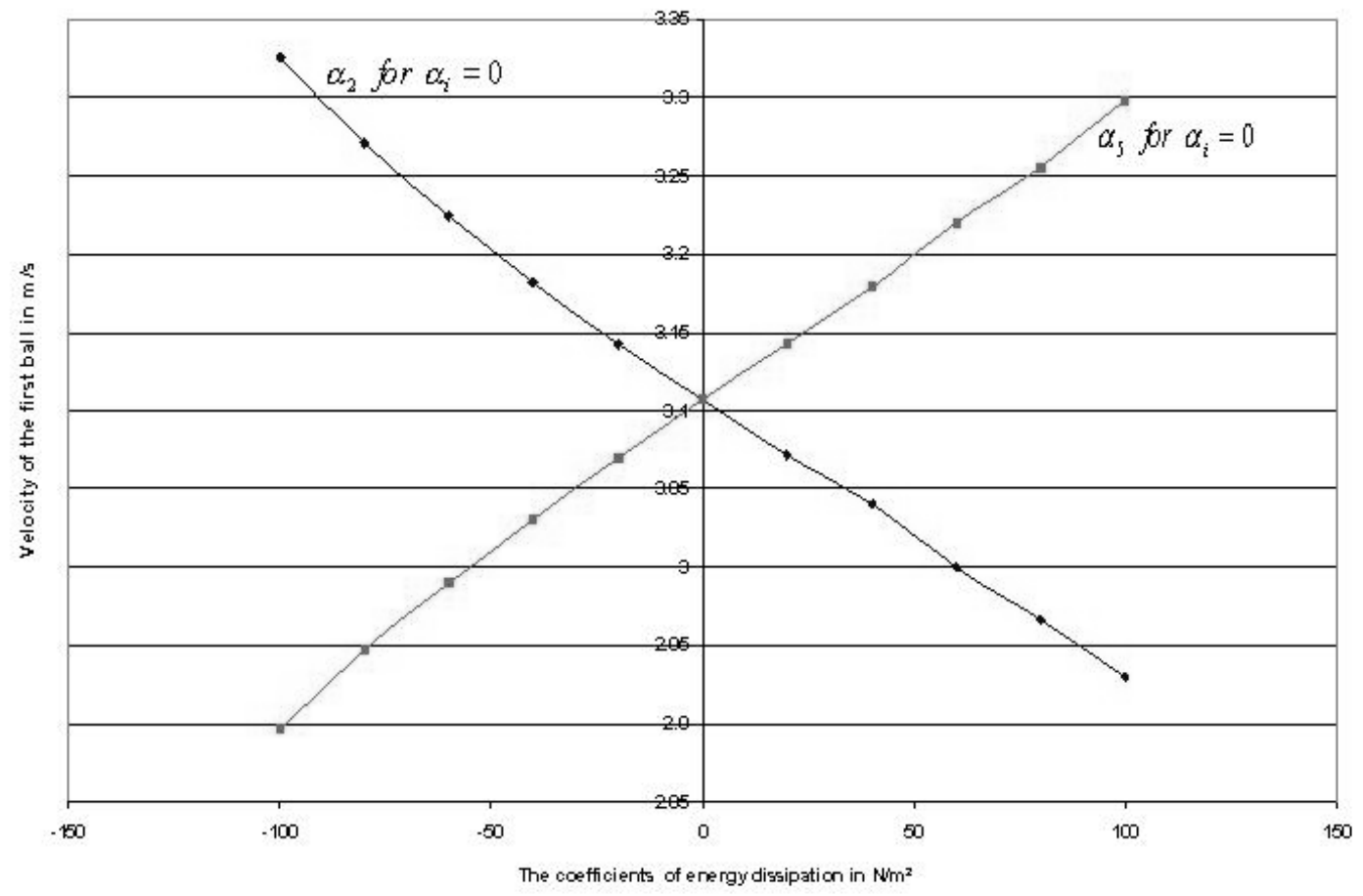

Fig. 5. Comparison between the coefficients of energy dissipation $\alpha_{2}$ and $\alpha_{5}$

When the first ball has an interaction with the massive obstacle through the second ball, the coefficients $\alpha_{2}$ or $\alpha_{5}$ is different from zero and all others $\alpha_{i}$ are zero. To understand the difference between these two coefficients of dissipation, we represent in Fig. 5 the velocity of the first ball after collision when the first one varies, while the other one is equal to zero, the other parameters are as follows: $m_{1}=0.001 \mathrm{~kg}$ et $m_{2}=m_{3}=15 \mathrm{~kg}$, $m_{4}=510^{6} \mathrm{~kg}, K_{12}=7 \mathrm{~N} / \mathrm{m}^{2}, K_{23}=1 \mathrm{~N} / \mathrm{m}^{2}, K_{13}=5 \mathrm{~N} / \mathrm{m}^{2}, K_{24}=13 \mathrm{~N} / \mathrm{m}^{2}, K_{34}=$ $12 \mathrm{~N} / \mathrm{m}^{2}, K_{14}=1500 \mathrm{~N} / \mathrm{m}^{2}$ and $\mathbf{a}=\mathbf{3 . 1 3 2 0 9} \mathbf{~ m} / \mathbf{s}$.

We observe the two coefficients allow to produce this phenomenon. The only difference is that $\alpha_{2}$ must be negative whereas $\alpha_{5}$ must be positive. Let us recall that these parameters are restricted by the conditions on matrix M. 


\subsection{Case 3.3: The three balls that bounce don't remain in contact after the collision}

The case of the three balls bounce and don't remain in contact after the collision, Fig. 6, is investigates numerically because the formal calculation is too heavy. Let us suppose that the three balls fall on the massive obstacle of a height $h=0.5 \mathrm{~m}$, i.e. with the velocity before the collision $\mathbf{a}=\mathbf{3 . 1 3 2 0 9} \mathbf{~ m} / \mathbf{s}$. Let's consider, as always, that the mass of the first ball is very small $m_{1}=0.001 \mathrm{~kg}$ whereas the mass of the massive is very large $m_{4}=510^{6} \mathrm{~kg}$. We assume the $\alpha_{4} \neq 0$ and the others $\alpha_{i}=0$.

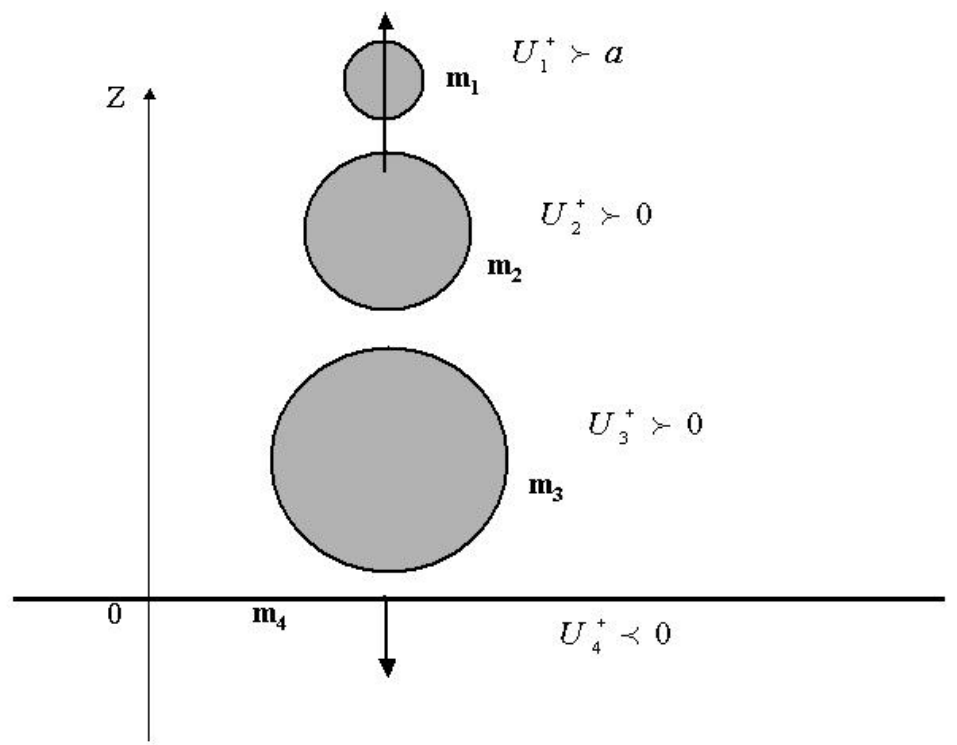

Fig. 6. The three balls bounce and don't remain in contact after the collision

We choose the masses $m_{2}=10 \mathrm{~kg}$ and $m_{3}=15 \mathrm{~kg}$ and the coefficients of energy dissipation $K_{12}=7 \mathrm{~N} / \mathrm{m}^{2}, K_{23}=10 \mathrm{~N} / \mathrm{m}^{2} K_{13}=7 \mathrm{~N} / \mathrm{m}^{2}, K_{24}=13 \mathrm{~N} / \mathrm{m}^{2}, K_{34}=10 \mathrm{~N} / \mathrm{m}^{2}$, $K_{14}=1500 \mathrm{~N} / \mathrm{m}^{2}, \alpha_{4}=-100 \mathrm{~N} / \mathrm{m}^{2}$ and the all others coefficients are zero such as the matrix of energy dissipation $\mathrm{M}$, definite from the pseudo-potential of energy, is positive semi-definite and the conditions of actual evolutions are verified. By resolution of a linear system, the unknown vector of the velocities of the four balls after the collision is

$$
\left\{\begin{array}{l}
U_{1}^{+}=\mathbf{3 . 3 0 6 9} \mathrm{m} / \mathrm{s} \\
U_{2}^{+}=0.4478 \mathrm{~m} / \mathrm{s} \\
U_{3}^{+}=0.2849 \mathrm{~m} / \mathrm{s} \\
U_{4}^{+}=-0.000017 \mathrm{~m} / \mathrm{s}
\end{array}\right.
$$

The velocity $U_{1}^{+}$is larger than to the velocity before the collision. Thus the superball phenomenon is accounted in this case. The velocity of the fourth ball is negative and is 
very weak, which is in agreement with the conservation of the quantity of motion. The velocities $U_{2}^{+}$and $U_{3}^{+}$verify the impenetrability condition.

Now we let coefficient $K_{34}$ vary and we fixed the other parameters. The results are shown on Fig. 7.

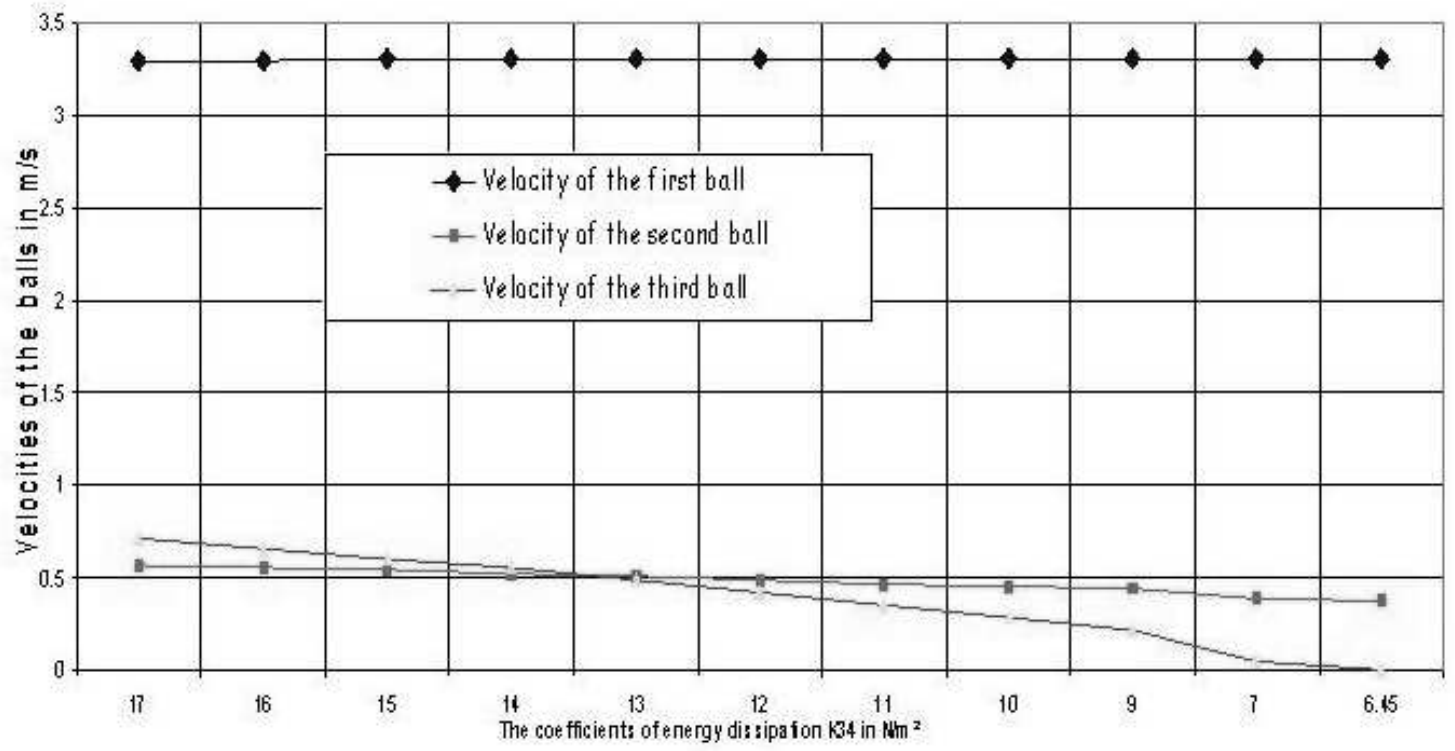

Fig. 7. Evolution of the velocities of the three balls according to the coefficient $K_{34}$

One notices that the velocity of the first ball increases weakly by decreasing the coefficient $K_{34}$. On the other hand, the velocities of the balls 2 and 3 decrease.

- If $K_{34}>13.5 \mathrm{~N} / \mathrm{m}^{2}$; the impenetrability condition is not verified, because $U_{3}^{+}>U_{2}^{+}$.

- If $K_{34}=13.5 \mathrm{~N} / \mathrm{m}^{2}$; the velocities of the two balls 2 and 3 are equal, i.e. these two balls remain in contact after the collision (Case 3.2).

- If $6.45<K_{34}<13.5 \mathrm{~N} / \mathrm{m}^{2}$; the impenetrability condition is verified, because $U_{3}^{+}<U_{2}^{+}$.

- If $K_{34}=6.45 \mathrm{~N} / \mathrm{m}^{2}$; the third ball remains in contact with the massive obstacle (Case 2.2).

\section{CONCLUSION}

The collision of four aligned rigid balls was studied. A system formed by these rigid balls is deformable, since its shape changes because the relative distances of the different bodies change. The superball phenomenon is produced according to different cases such as the interaction between the first ball and the massive obstacle must be presented. For every cases of evolutions of the balls after the collision, has been investigated the relations on the physical parameters which insure the superball phenomenon. These relations are obtained on the basis of the fundamental hypothesis: the mass of the first ball is very small whereas the mass of the massive obstacle is very large. 


\section{ACKNOWLEDGEMENTS}

This research was developed within the framework of Lagrange Laboratory, an European research group between CNRS, CNR, University of Rome "Tor Vergta", University of Montpellier II, ENPC and LCPC. The authors wishes to thank Professeur Franco Maceri for the scientific discussions and for his valuable comments on this paper.

\section{REFERENCES}

[1] J. Walker, Rigid bodies collision, Science Am., 259,116, (1988).

[2] M. Frémond, Collisions, Dipartimento di Ingegneria Civile, Università Tor Vergata, Roma (2006).

[3] M. Frémond, Rigid bodies collision, Physics letters, 204(1) (1995) 33-41.

[4] C. Cholet, Collision d'un point et d'un plan, C.R.Academic Science., Srie I:, 328(5) (1999) 445-458.

[5] M. Frémond, Non-smooth thermodynamics, Spinger Verlag, Heidelberg (2002).

[6] J. J. Moreau, Sur les lois de frottement, de viscosité et de plasticité,. C. R. Acad. Sci., Paris 271 (1970) 608-611.

[7] J. J. Moreau, Fonctionnelles convexes, Dipartimento di Ingegneria Civile, Università Tor Vergata, Roma, (2003).

Received June 8, 2010

\section{SỰ VA CHẠM CỦA BỐN QUẢ CẦU XẾP THẨNG HÀNG}

Bài báo này trình bày kết quả nghiên cứu về sự va chạm của bốn quả cầu xếp thẳng hàng. Kết quả nghiên cứu này dựa trên ý tưởng cơ bản là hệ vật rắn sẽ biến dạng khi hình dạng của hệ thay đổi do khoảng cách tương đối giữa các vật thay đổi. Một luật ứng xử tuyến tính đơn giản, mô tả bởi hàm tựa thế năng tiêu tán dựa trên điều kiện không xuyên qua nhau được giữa các quả cầu được sử dụng. Đã xét trường hợp khi ba quả cầu rơi vào vật cản nặng. Xét quả cầu thứ nhất có khối lượng rất nhẹ nảy trở lại với vận tốc lớn hơn nhiều vận tốc rơi của nó, Trường hợp này đôi khi được gọi là hiện tượng "siêu cầu". Hiện tượng này được sinh ra từ các trường hợp khác nhau như sự tương tác giữa quả cầu thứ nhất và vật cản nặng. Sự tương tác giữa quả cầu thứ nhất và vật cản nặng qua quả cầu thứ hai hoặc thứ ba, hiện tượng "siêu cầu" được tạo ra từ tất cả các trường hợp xảy ra sau khi va chạm. Mối liên hệ về các tham số vật lý đảm bảo hiện tượng "siêu cầu" đó được nghiên cứu ở tất cả các trường hợp xảy ra sau khi va chạm. Những mối liên hệ thu được dựa trên giả thuyết cơ bản: khối lượng của quả cầu thứ nhất nhỏ hơn rất nhiều so với khối lượng của vật cản. 